\title{
The Role of Biological Agents in Immunotherapy
}

\section{Imran Haruna Abdulkareem*}

Department of Trauma and Orthopaedic Surgery, Leeds General Infirmary, Great George Street, Leeds, UK

\begin{abstract}
Many autoimmune diseases and cancers have an underlying immune basis, and these include Systemic Lupus Erythematosus (SLE), rheumatoid arthritis, systemic sclerosis, ankylosing spondylitis, as well as breast cancer. Biological therapies are monoclonal antibodies and fusion proteins which contain specific recognition components that have antibody function. This principle takes advantage of antigen specificity to produce monoclonal antibodies to the desired antigen. Problems of biological therapies include ethical, regulatory, and licensing issues, documentation of trials, funding, adverse effects, media attention and publicity, selection issues, time considerations and risk-benefit analysis. Therefore, proper and strict regulation of research on humans as well as use of these biological agents should be carefully enforced and monitored by the authorities, to ensure maintenance of transparency and good standards.
\end{abstract}

Keywords: Biological agents; Immunotherapy; Monoclonal antibodies; Autoimmune diseases; Cancers; Adverse effects; Regulations

\section{Introduction}

Many diseases have been observed to have an underlying immune basis and include auto-immune diseases like systemic lupus erythematosus (SLE), rheumatoid arthritis and systemic sclerosis [1]. Auto-reactive $\mathrm{T}$ cells are kept under control by the regulatory $\mathrm{T}$ cells ( $\mathrm{T}_{\text {reg }}$ cells) and absence of co-stimulatory signalling leads to loss of $\mathrm{T}_{\mathrm{res}}$ cells [2]. CD28 super-agonists have been observed to cause selective expansion and activation of the regulatory $\mathrm{T}$ cells over conventional $\mathrm{T}$ cells ( $\mathrm{T}_{\text {conv }}$ cells) and so it was thought that this anti-CD28 antibody represented a promising new treatment option for the large number of human auto-immune diseases [3].

\section{The co-stimulatory signal}

Bretscher and Cohn in 1970 proposed the two signal model of lymphocyte activation to enable understanding of self/non-self discrimination, and this model suggested that $\mathrm{T}$ cell activation needs two separate signals. The first is transmitted through the $\mathrm{T}$ cell receptor (TCR) following binding of antigen, and the second co-stimulatory signal occurs through the binding of a separate receptor (CD28) on the $\mathrm{T}$ cell [4]. It has been observed that antigenic stimulation of the $\mathrm{T}$ cells without this co-stimulatory signal will result in a state of unresponsiveness called anergy and the anergic $\mathrm{T}$ cells fail to produce interleukin 2 (IL-2) and other cytokines required for $\mathrm{T}$ cell function and regulation [5]. CD28 is important for regulating immune responses and maintaining peripheral tolerance. Binding of this receptor to its ligands causes increased expression of CTLA-4 (Cytotoxic T lymphocyte antigen-4), which has a negative effect on $\mathrm{T}$ cell activation. This binding facilitates the differentiation of $\mathrm{Th}_{2}$ cells which have protective functions in auto-immunity, as well as control of the regulatory $\mathrm{T}$ cells [6].

\section{What is CD28?}

First cloned by Arrufo and Seed in 1987, and initially called TP44, this is a protein that belongs to the IgSF (immunoglobulin superfamily) group of receptors with a molecular weight of $44 \mathrm{KDa}$. It is expressed by sub-populations of $\mathrm{T}$ cells and activated B lymphocytes [7], as well as neutrophils and [3]. It is expressed before activation of T cells takes place.The ligands for this receptor are CD80/CD86 (B7.1 and B7.2) co-stimulators which are generally found on antigen presenting cells (APCs), and also bind to the counter-stimulatory receptor CTLA4 that is expressed after $\mathrm{T}$ cell activation to produce a negative effect. CTLA-4 has higher affinity for the ligands (B7.1 and B7.2) than CD28 and leads to blockade of further activation signal [5]. B7.2 (CD86) is the predominant co-stimulatory ligand for CD28 [4].

\section{Consequences of CD28-B7 Interaction}

CD28 stimulation causes transcriptional activation and posttranslational stabilisation of mRNA leading to increased expression of cytokines such as interleukin 2 (IL-2) and activation of protein kinase AKT [4]. It also prevents anergy and causes induction of the anti-apoptotic factor $\mathrm{BCL}_{\mathrm{XL}}$, contributes to $\mathrm{B}$ cell differentiation, antibody production, direction of $\mathrm{T}$ cell migration and the regulation of chemokine receptors [6].

\section{The Role of regulatory $\mathrm{T}$ cells}

These are $\mathrm{CD} 4{ }^{+} \mathrm{CD} 25^{+}$cells with regulatory function and known as $\mathrm{T}_{\text {regs }}$. They make up to about $5-15 \%$ of the peripheral CD4 ${ }^{+} \mathrm{T}$ cells. They constitutively express the interleukin 2 receptor- $\alpha$ chain (CD25) and CTLA-4. The development and survival of these cells in the thymus is controlled by $\mathrm{CD} 28$, which maintains their function independent of CTLA-4. This is important in the maintenance of tolerance, prevention of auto-immunity, enhancement of $\mathrm{T}$ cell response to pathogens, and prevention of transplant rejection [6]. In addition to that, the CD28mediated up-regulation of the inhibitory molecule CTLA-4 prevents potentially harmful inflammation by terminating normal immune responses [4].

\section{Molecular properties of CD28 “super-agonist"}

The super-agonist anti-CD28 antibody has been observed to bind to a lateral membrane -proximal loop of the molecule (C"D loop) and

*Corresponding author: Imran Haruna Abdulkareem, Department of Trauma and Orthopaedic Surgery, Registrars' office, B Floor Clarendon Wing, Leeds General Infirmary, Great George Street, Leeds, UK, E-mail: imranharuna@yahoo.com

Received April 20, 2013; Accepted May 18, 2013; Published May 25, 2013

Citation: Abdulkareem IH (2013) The Role of Biological Agents in Immunotherapy. Metabolomics 3: 116. doi:10.4172/2153-0769.1000116

Copyright: (C) 2013 Abdulkareem IH. This is an open-access article distributed under the terms of the Creative Commons Attribution License, which permits unrestricted use, distribution, and reproduction in any medium, provided the original author and source are credited. 
interaction of the antibody with the extracellular domain of human CD28 leads to a linear complex formation. The conventional antiCD28 antibodies bind CD28 bivalently, but result in the formation of tangled complexes. Complex formation of the CD28 causes aggregation of stimulatory signalling components such as PI3 kinase and growth factor receptor bound protein ( Grb 2) leading to generation of strong activating signal.

\section{Rationale for using anti-CD28 antibody}

Monoclonal antibodies and fusion proteins with specificity for the $\mathrm{T}$ cell receptor (TCR) and CD28 have been found promising in the treatment of auto-immune diseases [1]. Both the anti-TCR monoclonal antibodies and the "conventional" anti-CD-28 monoclonal antibodies individually are unable to stimulate the T cells and need to be combined to produce $\mathrm{T}$ cell activation and cytokine production. But the CD28 "super-agonists" are able to cause T cell activation without the need for TCR stimulation, hence the name super-agonists. This is why it was thought by many workers that these monoclonal antibodies will have a place in the treatment of auto-immune diseases which are refractory to the conventional treatments available to patients [3].

It has been observed that CD28 super-agonist administration in vivo causes selective expansion and strong activation of the naturallyoccurring $\mathrm{CD}^{+} \mathrm{CD} 25^{+} \mathrm{CTLA}-4^{+} \mathrm{FOXP}_{3}{ }^{+} \mathrm{T}_{\text {reg }}$ cells over conventional $\mathrm{T}$ cells ( $\mathrm{T}_{\text {conv }}$ cells), and absence of this signalling leads to loss of these regulatory cells. Also, a functional and/or numerical deficit in $\mathrm{T}_{\text {reg }}$ cells compared to pathogenic auto-reactive cells leads to initiation of autoimmunity. Therefore, it is believed that because $\mathrm{T}_{\text {reg }}$ cells are the main controllers of peripheral self tolerance, this new therapy which aims at re-establishing the balance between auto-reactive $\mathrm{T}$ cells and $\mathrm{T}_{\text {reg }}$ cells could have important contributions in the treatment of auto-immune diseases [2].

Furthermore, application of CD28 super-agonists was noted to result in momentary increase in the percentage of $\mathrm{T}_{\text {reg }}$ cells which was dose-dependent. This preferential expansion of $\mathrm{T}_{\text {reg }}$ cells over $\mathrm{T}_{\text {conv }}$ is thought to result from generation of extremely strong or sustained signal in $\mathrm{T}_{\text {reg }}$ cells following super-agonistic anti-CD28 stimulation. This is in addition to the production of $\mathrm{BCL}_{-\mathrm{xL}}$ which is an anti-apoptotic factor that prevents cell death. Also, increased interleukin synthesis by $\mathrm{T}_{\text {conv }}$ cells and its uptake by the $\mathrm{T}_{\text {reg }}$ cells are thought to contribute to the preferential expansion of the latter cells following super-agonistic CD28 stimulation [4]. Beyersdorf et al. [2] also suggested that $\mathrm{T}_{\mathrm{reg}}$ cells may have selective advantage over $\mathrm{T}_{\text {conv }}$ cells because of active suppression of the latter during super-agonistic CD28 stimulation by activating the cell contact-dependent suppressor machinery which only functions upon recognition of self antigens in vivo.

Lastly, it has been observed that administration of CD28 super-agonist to animals with EAE (experimental auto-immune encephalomyelitis) and experimental auto-immune neuritis (EAN) which resemble multiple sclerosis and Gullain-Barre syndrome respectively, prevented or reduced the clinical symptoms when given before the onset of the disease. This monoclonal antibody also rapidly stopped the disease progression and produced disease remission even after the onset of symptoms [2]. This evidence was supported by adoptive transfer experiments which revealed that transfer of CD28 super-agonist-activated $\mathrm{T}_{\text {reg }}$ cells protected recipient animals from the clinical signs of EAE, and $\mathrm{CD}^{+} \mathrm{CD} 25^{-} \mathrm{T}$ cells $\left(\mathrm{T}_{\text {conv }}\right)$ cells were observed to lack any protective effect in spite of ten times greater dose of administration [8].
Because both the pharmaco-dynamics and toxicological profiles of the CD28 super-agonist suggested that it was safe, it was thought to have clinical relevance in patients with multiple sclerosis and rheumatoid arthritis who are known to have deficits in $\mathrm{T}_{\text {reg }}$ cell numbers and/or function with the aim of curing them. The hope was that these patients might benefit from a boost in their $\mathrm{T}_{\text {reg }}$ cells following the super-agonist administration to improve their clinical symptoms [1,2].

\section{What are biological therapies?}

These are monoclonal antibodies and fusion proteins which contain specific recognition components that have antibody function. The principle of biological therapy takes advantage of antigen specificity to produce monoclonal antibodies to the desired antigens [1]. Currently used biological therapies in clinical practice include Adalimumab, Etanercept, Infliximab, Rituximab, Ibritumomab tiuxetan, Tositumomab and Iodinated Tositumomab (I-131), Basiliximab, Daclizumab, Alemtuzumab, Cetuximab, Bevacizumab, Trastuzumab, and Palivizumab [1].

\section{Sources of biological therapies}

Kohler and Milstein first developed hybridoma technology in early 1970s, and set the pace for the development of monoclonal antibody therapeutics. This was followed later on by the development of hybridomas by the fusion of $B$ cells from immunised mice with murine myeloma cell lines. The immortalised cell lines (clones) were then selected according to the antibody of interest which is then produced in large quantities. This came with problems because it was difficult to produce human anti-mouse antibodies that can be used without immunogenic complications [5].

Genetic manipulations allowed the development of chimeric antibodies which are obtained from a combination of murine variable-region genetic material with human constant-region genes. A combination of murine CDR genetic material with the remaining part of the antibody obtained from humans results in humanised antibodies. Lastly, fully human monoclonal antibodies have their origin completely from human beings [1]. Humanised antibodies are superior because they have better interaction with human $\mathrm{Fc}$ receptors and effector cells, which gives a greater effector function and less immunogenic reaction. This prolongs the therapeutic half-life of the drug and reduces the side effects especially following subsequent exposures [1].

The function of the monoclonal antibody can be determined by selecting a particular Fc component. This can be coupled with a specific molecule to form a fusion protein that has both the antibody effector function and any other desired effects. Finally, monoclonal antibodies can be changed and used for immunotherapy by labelling them with toxins specific for cancer cells without affecting the normal cells [7].

\section{Problems of biological therapies}

Biological therapies are associated with a lot of problems which include regulatory/licensing issues, documentation of the trials (recording and reporting), funding, side effects and complications (short- and long-term), ethical considerations, media attention and publicity, selection of the immune component to be modified, time considerations, risk-benefit analysis and when to use the therapy [1] I shall therefore attempt to briefly highlight each of the issues involved.

\section{Regulatory and Licensing Issues}

Biological therapies are potentially harmful agents and so there is need for involvement of licensing and regulatory agencies like the 
UK Medicines and Healthcare Products Regulatory Agency (MHRA), and independent research ethics board (REB) right at the beginning of conception of the idea through to the pre-clinical and clinical studies [9]. This will help to create checks and balances and highlight any potential hazardous effects of the agent before it is tried on humans. This protocol has been observed in the case of TGN1412 because three independent bodies reviewed the drug before it was tried in the six volunteers. It is also important for drug investigators and sponsors to provide accurate, complete and unbiased information to the regulatory bodies and ensure transparency throughout the development of new drugs, in addition to the need for compulsory registration and disclosure of the trials and protocols to the regulatory agencies and public [10].

\section{Problems of Funding}

It is important to note that the process of drug development is very expensive and capital intensive [1], hence the need for research grants and financial support from governments, international agencies and pharmaceutical companies, which will help to convert the idea into a finished product ready for use. In addition to that, even the trials (both pre-clinical and clinical) are capital intensive and add to the cost of drug manufacturing. Lastly, use of the drug is also expensive because it has to be procured by the governments or sometimes the individuals have to pay for the drug according to its availability, this may be worsened by the added treatment of side effects and complications. In addition to all that, the cost of not treating the patient also needs to be considered as it may be more expensive than treating the patient with the therapy in question.

\section{Side Effects of the Drugs}

Safety issues in drug trials are of utmost importance, because of the possible side effects which can be short- or long-term. Any system can be affected depending on the type of monoclonal antibody used and its intended target(s). Immunosuppression can lead to fungal and opportunistic infections, involvement of the gastro-intestinal system may lead to nausea, vomiting, and diarrhoea, while affectation of the respiratory system will lead to difficulty in breathing, chest pain and even respiratory as well as cardiovascular failure. In addition to that shock and hypovolaemia may result in acute renal failure which may present in decreased or complete lack of urine formation [1].

Occasionally, multiple organ failure can occur with affectation of virtually all the systems at once as can be seen in the case of trial with TGN1412 [10]. Within 90 minutes of receiving this monoclonal antibody, all the six volunteers developed a systemic inflammatory response syndrome as evidenced by headache, myalgias, nausea, diarrhoea, erythema, vasodilatation and hypotension. There was also recurrent fever, respiratory difficulty, cardiovascular shock, renal failure, hospital-acquired infections, peripheral ischaemia, disseminated intravascular coagulation and generalised skin desquamation [11]

Long-term side effects and complications are also to be expected in some cases and these can include chronic low blood cell count, anaemia, cancers, autoimmune diseases, decreased life expectancy and resurgence of infections like tuberculosis in patients that received anti-TNF $\alpha$ therapy [1]. This is because TNF- $\alpha$ is required for the formation of localised tuberculous granuloma, which helps to localise the infection in one place and so may remain dormant for a long time.

\section{Ethical Considerations}

These are very important issues to be considered so as to be sure the subject/patient is given his/her right to know and make judgements before any clinical trials can be done on them. This can be complicated by the need to reward or pay the subjects for their participation which many believe can cloud or bias their judgements in taking a reasonable decision to partake in a drug trial [10]. But Emanuel and Miller [9] caution that although the role of money cannot be over-emphasised, bad things can happen in ethical research, but money does not make them unethical, unscrupulous or malignant. They further noted that a research is ethical from the beginning, good outcomes do not necessarily make it ethical, and a bad outcome does not make an ethical research unethical. Among the many ethical issues to be considered include the need to conduct research in a particular disease area and whether it is justified. Others are the need for scientific validity which require that pre-clinical studies are conducted using cell cultures and laboratory animals before clinical trials are carried out, fair subject selection should be done without targeting vulnerable and marginalised communities, taking informed consent and respecting the enrolled participants as well as granting them the right to withdraw from any trials at any time $[1,9]$.

\section{Risk-benefit analysis}

It is important to make a careful assessment in order to weigh the risks of any drug use against the benefits so as to avoid mistakes and end up with litigation. In the case of the TGN1412 phase 1 clinical trial, healthy male adult volunteers were used even though the drug was meant for patients with compromised immune systems, and therefore some felt that real patients who stood to benefit from the drug should have been co-opted into the trial [10]. But Emanuel and Miller [9] suggested that even though the volunteers had no chance of benefiting directly from the trials (medically), the medical knowledge to be gained could be used to justify the risk of the trials.

\section{Media Publicity}

Although it is important for drug developers to be open and transparent during drug research, negative media attention and bad publicity need to be discouraged, in order to prevent fear and panic in the public which can lead to refusal or rejection of new therapies. It is important for health personnel to educate themselves and their patients on the benefits and/or hazards of new therapies and how they work. This will ensure patient's trust and compliance with medication, an important consideration in their treatment to ensure good outcomes [9].

\section{Conclusion}

Anti-CD28 monoclonal super-agonist and other biological agents have definite roles in the treatment of auto-immune diseases and even cancers, because of their ability to enhance regulatory $\mathrm{T}$ cell function, but there is need to carry out careful and meticulous pre-clinical trials before trying them on humans under close observation, given to one person at a time to prevent disastrous outcomes. Proper and strict regulation of research on humans, as well as use of these biological agents should be enforced and monitored by the authorities to ensure maintenance of transparency and good standards.

\section{References}

1. Johnston SL (2007) Biologic therapies: what and when? J Clin Pathol 60: 8-17.

2. Beyersdorf N, Hanke T, Kerkau T, Hünig T (2005) Superagonistic anti-CD28 antibodies: potent activators of regulatory $T$ cells for the therapy of autoimmune diseases. Ann Rheum Dis 64: 91-95.

3. Mehrishi JN, Szabó M, Bakács T (2007) Some aspects of the recombinantly 
expressed humanised superagonist anti-CD28 mAb, TGN1412 trial catastrophe lessons to safeguard mAbs and vaccine trials. Vaccine 25: 3517-3523.

4. Green JM (2000) The B7/CD28/CTLA4 T-cell activation pathway. Implications for inflammatory lung disease. Am J Respir Cell Mol Biol 22: 261-264.

5. Male D, Brostoff J, Roth D, Roitt I (2012) Immunology. (8thedn) Elsevier Limited, Canada.

6. Bour-Jordan H, Blueston JA (2002) CD28 function: a balance of costimulatory and regulatory signals. J Clin Immunol 22: 1-7.

7. Delves PJ, Martin SJ, Burton DR, Roitt IM (2006) Roitt's Essential Immunology. (11thedn) Blackwell Publishing, Oxford 176-180.
8. Lin $\mathrm{CH}$, Hunig T (2006) Efficient expansion of Regulatory T cells in vitro and in vivo with a CD28 superagonist. Eur J Immunol 33: 626-638.

9. Emanuel EJ, Miller FG (2006) Money and distorted ethical judgments about research: ethical assessment of the TeGenero TGN1412 trial. American J Bioeth 7: 76-81.

10. Goodyear M (2006) Learning from the TGN1412 trial. BMJ 332: 677-678.

11. Suntharalingam G, Perry MR, Ward S, Brett SJ, Castello-Cortes A, et al (2006) Cytokine storm in a phase 1 trial of the anti-CD28 Monoclonal Antibody TGN1412. N Engl J Med 355: 1018-1028. 